\title{
NSAIDs; Safety and Risk Assessment in CVS Events, Comparisons and Facts
}

\author{
Hina Hasnain ${ }^{1}$, Huma Ali ${ }^{1}$, Anum Tariq ${ }^{1}$, Farya Zafar ${ }^{1}$ and Safila Naveed ${ }^{2 *}$ \\ ${ }^{1}$ Ziauddin University, Karachi, Pakistan \\ ${ }^{2}$ Jinnah University for Women, Karachi, Pakistan
}

\begin{abstract}
Products of Non-steroidal anti-inflammatory drugs (NSAIDs) are principally and most widely utilized due to their multipurpose actions, i.e., analgesic anti pyretic and anti-inflammatory effect. Beside their therapeutic effect their toxic effect based on their selectivity of cyclooxygenase (COX) enzyme. While cardiovascular toxicities associated with NSAIDs are mainly related with COX-2 selective inhibitor and primarily dependent on their dose time and duration. Variability in therapeutic response and susceptibility to toxicity is well recognized and can be manageable if considerable precautions implement.
\end{abstract}

Keywords: Non-steroidal anti-inflammatory; Celecoxib; Cardiovascular

\section{Introduction}

In conditions like fever, pain, headache, arthritis, lupus disease and other inflammatory problems, there are numerous drugs which have frequently been recommended from the class of therapeutic agents known as non-steroidal anti-inflammatory drugs [1]. Aspirin (the proto type drug of this class) and other NSAIDs have become the cornerstone therapy to avert any thrombotic and cardiological episodes in majority of high risk sick population [2]. Although, NSAIDs are effective and beneficial in outline pathological conditions, prolonged use of NSAIDs are highly associated with severe side effects. However, many of these side effects can be prevented by careful management and by implementation of preventive strategies.

\section{Mechanism of Action}

The clinical effects of non-steroidal anti-inflammatory were first described by Vane and Piper. They suggest that NSAIDs inhibit the biosynthesis of prostanoids by inhibiting the enzyme cyclooxygenase (COX). Arachidonic acid is the substrate for COX enzyme lead to the formation of prostanoids including prostaglandins, prostacyclins, and thromboxanes [3]. Different isoform have been discovered [4] out of which COX-1 (PGHS-1) and COX-2 (PGHS-2) are the two allied COX enzymes which have been delineated. In sequences of amino acids, both of these isoforms have $60 \%$ homology that conserved for the arachidonic acid catalysis [5-9]. Both of these isoforms serves as a catalyst in converting arachidonic acid to COX-2 which results in formation of prostaglandin, the biologically active form. Out of the two, the first isoform; prostaglandin $\mathrm{H}_{2}$ Synthase-1 (PGHS-1) is the major and exclusive loci for non-steroidal anti-inflammatory drug activity but the second isozyme; PGH Synthase-2 (PGHS-2) is also sensitive to actions of NSAIDs which is also recognized with-it.

Anti-inflammatory glucocorticoids inhibit the expression of COX-2 which further explains the involvement of this enzyme in inflammation. One of the possible mechanisms for pinpointing the secure and more viable use of non-steroidal anti-inflammatory drugs arises from such findings that both the isoforms of COX enzyme can be segregate halted. Drugs which are inhibitors of PGHS-2 are the inflammation reducing agents and on the other hand they reserve the synthesis of PG by kidneys and stomach and therefore decrease unfavorable adverse reactions which are most frequently linked with NSAIDs
[10]. Physiological stimuli including shear stress in vasculature and ovulation regulate both isoforms $[11,12]$. The enzyme COX-1 involve in various physiological conditions including mucosal protection and cardiovascular protection, while, certain processes of inflammation brings about COX-2 enzyme in turn the products of this isoform involve in growth factors, lymphokines and other inflammatory mediators. In Hypertension, diabetes mellitus (DM), bone fracture, heart failure and similar pathological conditions and even in non-pathological kidneys, there is enhanced interrelation of mRNA and proteins of COX-2 enzyme [13].

Therapeutic and harmful activities are linked with the suppression of COX enzyme. Studies suggested that actions of non-steroidal agents against inflammations are because of suppression of COX-2 whereas, the dwindling of COX-1 lead to stomach lining irritation [14].

\section{Classification of NSAIDS}

Based on the characteristics including chemical (Table 1) and pharmacological properties and (Table 2) show the classification of NSAIDs on the bases of selectivity toward COX enzymes $[15,16]$.

\section{Mechanism of Cardiovascular Toxicity of NSAIDS}

It is believed that at therapeutic doses, COX-2 enzyme inhibitors halt COX-2 isozyme but it results in metabolic disturbances which leads to the over production of by products that are deleterious and damages arterial wall and produces arterial blood clotting $[17,18]$. Leukotriene B4 and thromboxane A2 (TXA2) will be formed in significant amounts and prostacyclin (PGI2) from arachidonic acid will be synthesized very less when COX-2 is inhibited therefore this balancing tip allows TXA2 to function unopposed that results in higher risk for CV adverse

*Corresponding author: Safila Naveed, Faculty of Pharmacy, Jinnah University for Women, Karachi, Pakistan, Tel: 0092-03002621917; E-mail: safila117@yahoo. com

Received November 25, 2015; Accepted January 27, 2016; Published February 04, 2016

Citation: Hasnain H, Ali H, Tariq A, Zafar F, Naveed S (2016) NSAIDs; Safety and Risk Assessment in CVS Events, Comparisons and Facts. J Bioequiv Availab 8: 084-088. doi:10.4172/jbb. 1000273

Copyright: @ 2016 Hasnain $\mathrm{H}$, et al. This is an open-access article distributed under the terms of the Creative Commons Attribution License, which permits unrestricted use, distribution, and reproduction in any medium, provided the original author and source are credited. 
Citation: Hasnain H, Ali H, Tariq A, Zafar F, Naveed S (2016) NSAIDs; Safety and Risk Assessment in CVS Events, Comparisons and Facts. J Bioequiv Availab 8: 084-088. doi:10.4172/jbb.1000273

\begin{tabular}{|c|c|}
\hline Groups & Example(s) \\
\hline Salicylates & $\begin{array}{l}\text { Acetyl salicylic acid, } \\
\text { Sulfasalazine }\end{array}$ \\
\hline $\begin{array}{l}\text { Propionic acid derivatives } \\
\text { Pyranocarboxylic acids }\end{array}$ & $\begin{array}{l}\text { Ibuprofen, naproxen, } \\
\text { ketoprofen, flurbiprofen, } \\
\text { fenoprofen, Oxaprozin. }\end{array}$ \\
\hline Heteroaryl acetic acid & $\begin{array}{c}\text { Etodolac } \\
\text { Tolmetin, diclofenac, } \\
\text { ketorolac }\end{array}$ \\
\hline Alkanones & Nabumeton \\
\hline Indoleacetic, Indeneacetic acids & Indomethacin, sulindac, etodolac \\
\hline $\begin{array}{c}\text { Oxicams } \\
\text { Pyrroloppyrrole }\end{array}$ & $\begin{array}{l}\text { Piroxicam, meloxicam } \\
\text { Ketorolac }\end{array}$ \\
\hline Fenamates & $\begin{array}{c}\text { Mefenamic acid, meclofenamic } \\
\text { acid }\end{array}$ \\
\hline Diaryheterocycles & $\begin{array}{l}\text { Rofecoxib, celecoxib, } \\
\text { veldecoxib, paracoxib, } \\
\text { etoricoxib, lumaricoxib }\end{array}$ \\
\hline
\end{tabular}

Table 1: Chemical classification of NSAIDS.

\begin{tabular}{|c|c|}
\hline COX-1 Isoform & COX2/COX1 Ratio \\
\hline Ketorolac & - \\
\hline Flurbiprofin & 0.078 \\
\hline Ketoprofen & - \\
\hline Indomethacin & $2-167$ \\
\hline Acetyl Salicylic acid & $0.15-1.7$ \\
\hline Ibuprofen & 0.6 \\
\hline Naproxen & 122 \\
\hline Tenidap & COX2/COX1 Ratio \\
\hline CoX-2 Isoform & 30 \\
\hline Celecoxib & 4.0 \\
\hline Rofecoxib & 1.9 \\
\hline Etodolac & 0.33 \\
\hline Meloxicam & $0.6-2.2$ \\
\hline Diclofenac Na/K & - \\
\hline Sulindac & - \\
\hline Sodium salicylate & 33 \\
\hline Piroxicam & 15 \\
\hline Tenoxicam & \\
\hline
\end{tabular}

Table 2: Classification of NSAIDS based on their cox-1 or cox-2 selectivity [60]

events since TXA2 is vasoconstrictive and pro-aggregatory while PGI2 in vasodilatory and anti-aggregatory (Figure 1).

Side effects associated with cardiovascular system (CVS) and gastrointestinal (GI) mainly linked with the use of traditional nonsteroidal anti-inflammatory drugs and COX-2 enzyme inhibitors [19]. And there is virtually higher chance of CVS pathologies in the population of patients who administered the drug formulations of COX-2 inhibitors as revealed through many recent clinical trials but it is quite evident that that the hazards of GI issues are decreased by using the inhibitors of COX-2 enzymes [20-23].

In patients involving their cardiovascular system and having increased risk for such incidents, the main thing is the use of such agents that can give adequate hostage of toxicity prevention and fulfill provision of efficacy [24,25]. It was initially thought about COX2 inhibitors that they have lesser analgesic activity as compared to NSAIDs after the first appearance of the drug in market but soon it was become evident from the clinical data that most of inhibitors of enzyme COX-2 possess similar or quite superior effect of pain relief than the traditional non-steroidal anti-inflammatory agents, moreover it was verified through the table constructed by the Oxford pain group [26-28].

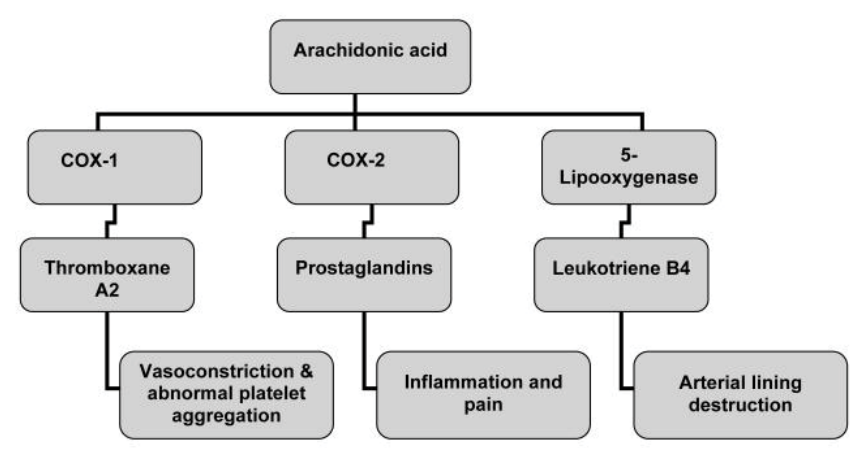

Figure 1: Cardiovascular toxicity mechanism [18].

When inhibition of prostacyclin takes place which is also an atheroprotective prostanoid, cardio-toxicity occurs and this is due to the administration of traditional as well as COX-2 selective nonsteroidal anti-inflammatory agents. The traditional non-steroidal agents along with coxibs frequently and selectively inhibits COX-2 enzyme which is also linked with the suppression of platelet COX-1 enzyme but it is not adequate to suppress the function of platelets and particularly this property of coxibs and traditional non-steroidal antiinflammatory agents mainly elucidates their apportioned CVS toxicities [29]. Non-steroidal anti-inflammatory agents having actions on both of the isoforms of COX enzyme are less appealing to use as compare to the drugs which are selective for COX-2 enzyme and this is due to the GI side effects of non-steroidal anti-inflammatory drugs targeting non-selectively both enzymes, hence the drugs that are particular for COX-2 enzyme suppression have equal actions against inflammation like the non-selective agents but unlike non-selective drugs, they have negligible harm to GI system [30].

The safety of drugs particularly suppressing the COX-2 enzymes and non-selective traditional agents regarding cardiovascular system have been a considerable topic to discuss therefore the higher chances for such cardiovascular incidents associated with the use of different formulations of Rofecoxib was highlighted following the influential trials like APPROV [31].

Hypertension and volume retention are also one of the multiple mechanisms like differences in endothelial functions and oxidative stress due to CV risks associated with NSAIDs [32]. The suppression of prostacyclin formation which is dependent on COX-2 enzyme inhibition without the dwindling of production of thromboxane due to COX-1 enzyme inhibition is due to the increased risks of thrombotic events caused by COX-2 selective inhibitors [32,33].

Ungprasert et al. in 2015 investigated the association of non-aspirin non-steroidal anti-inflammatory drugs and risk of hemorrhagic stroke. A range of observational studies were systematically evaluated and meta-analysis of selected studies was performed. It was concluded that NSAIDs as particular group was not connected with a notably eminent threat of hemorrhagic stroke. But, an amplified risk was reported in numerous moieties of NSAID preferentially in meloxicam and diclofenac users. Most profound risk was estimated in rofecoxib group of patients. Changes in hemodynamic pattern linked to NSAID utilization are extensively assumed as main contributing mechanism of adverse cardiovascular pathogenicity [34-36].

\section{Efficacy and Dosage}

Individual drug in NSAIDs group possess own therapeutic 
effectiveness and strength (optimal dose) for different conditions. The most common doses of NSAIDs prescribe ranging $200 \mathrm{mg}, 400 \mathrm{mg}, 600$ $\mathrm{mg}$ and $800 \mathrm{mg}$ (Table 3). The products of Celecoxib having shorter half-lives and administered in doses of once daily are less intruding with the COX-enzyme system than the drugs having half-lives longer and administration is in dosages of once daily or the drugs possess shorter half-lives prescribed in twice daily dosing regimen. This shows the clinical importance of pharmacokinetics of the drug [33]. These drugs are normally available over-the-counter for the suppression of conditions such as headache, back and joint pain, and menstrual pain.

Numbers of studies have been found to be evaluating the GI and cardiovascular safety of alternative dosing strategies such as alternate day dosing, once daily verses twice daily dosing or periodic drug holidays.

\section{Comparison and Facts of Different NSAIDS}

Prolong and high doses of NSAIDS have a wide range of adverse effect, mainly on alteration in GI, renal functions and CVS system [34]. However, those patients who are taking therapeutic dose of NSAIDS for shorter time tolerates them well [35]. Number of studies have been reported that the risk associated with the NSAIDs depend upon the intensity, dose and duration [36]. It was consider that the use of NSAIDs are associated with CV side effects however later it was found that only non-selective NSAIDs accompanying with CV adverse effects such as increased risk of myocardial infarction (MI) $[37,38]$. Conclusively, on the basis of the results of randomized control trials (RCTs), at higher doses the effects of NSAIDs, except for naproxen, showing links to high hazards for MI development and in those patient who were previously diagnosed with coronary heart disease but for diclofenac and Refecoxib risk associated is not dependent on doses [38].

High risk patient population including patients having congestive heart failure (CHF), hepatic and kidney disorders, patients administering diuretics and angiotensin converting enzyme inhibitors, are more prone to develop hypertension by using the drugs selectively targeting COX-2 enzyme [39]. Results of various RCTs emphasizes on evidence of the hazards which are associated with the use of nonsteroidal anti-inflammatory agents and inhibitors of COX-2 enzymes, explaining highest risk of MI was associated with Rofecoxib and lumiracoxib, stroke occurrence was found to be hooked up with the use of Ibuprofen and Diclofenac, while many of the cardiovascular events associated with use of Etoricoxin and Diclofenac. When the Diclofenac used in doses higher than needed for therapeutic response, risk of death was remarked through various RCTs [29].

Chronic utilization of non-steroidal anti-inflammatory drugs linked with various deleterious health issues. Summary of the results of a study showed that the relative risk of Rofecoxib in doses of less than and equals to $25 \mathrm{mg}$ with $95 \%$ Confidence Interval was found to be $1.33(1.00-1.79)$ while on the other hand when the dose was increased and greater than $25 \mathrm{mg}$ with similar confidence intervals, the relative

\begin{tabular}{|c|c|}
\hline NSAIDs & Clinical doses $(\mathbf{m g})$ \\
\hline Ibuprofen & $1,200-3000$ \\
\hline Diclofenac & $100-150$ \\
\hline Naproxen & $500-1000$ \\
\hline Meloxicam & $8-15$ \\
\hline Celecoxib & 200 \\
\hline Ketoprofen & $200-300$ \\
\hline Etoricoxib & 60 \\
\hline
\end{tabular}

Table 3: Clinical doses for the use of some NSAIDS. risk of CVS events associated with Rofecoxib was found to be 2.19 (1.64-2.91). Similarly, Celecoxib showed to have relative risk of 1.06 (0.91-1.23) with 95\% confidence interval while Diclofenac showed highest values of relative risks 1.40 (1.16-1.70) with 95\% confidence interval. Moreover Meloxicam and Piroxicam showed relative risks of $1.25(1.00-1.55)$ and $1.06(0.70-1.59)$ respectively. Ibuprofen showed 1.07 (0.97-1.18) and Indomethacin was found to have relative risk of 1.30 (1.07-1.60). Naproxen among all NSAIDs included in the study showed lowest relative risks of 0.97 (0.87-1.07) with $95 \%$ confidence interval. It showed that Rofecoxib was found to be most harmful in either dosage regimen and Naproxen was least dangerous contrary to which Diclofenac was on the top of the list for increasing hazards of $\mathrm{CV}$ toxicity [40-42].

Likewise, with various other trials including adenoma prevention with Celecoxib (APC) trial and the prevention of spontaneous adenomatous polyps (PreSAP) trial for evaluating the safety and efficacy of Celecoxib in cardiovascular events and blood pressure divulge, the hazard ratio was found to be $2.6 \%$ (95\% CI; 1.1-6.1) in the patients taking $200 \mathrm{mg}$ Celecoxib twice daily. The hazard ratio was found to be 3.4 (95\% CI, 1.5-7.9) in patients with Celecoxib dose of $400 \mathrm{mg}$ twice daily in APC trail and 1.3 (95\% CI, 0.6-2.6) in patients who had taken Celecoxib $400 \mathrm{mg}$ OD in PreSAP trail. Highly significant elevation in the systolic blood pressure was also shown by both dosage groups in APC trail while in PreSAP group no blood pressure changes were seen. Cardiovascular events and blood pressure is possibly raised up to two-folds by increasing doses of Celecoxib and there is meaningful reduction in $\mathrm{CV}$ events by administering lower doses or other dose intervals [43-46].

\section{Management of CVS Toxicities by NSAIDS}

In the presence of partial suppression of platelet COX-1, there seems to be a deep-seated suppression of COX-2 dependent PGI-2 and it put one's finger on the fact that this is the most credible process of cardiovascular risks and toxicities which are associated with the use of non-steroidal anti-inflammatory agents both selective and nonselective [47,48]. The use of a biomarker strategy of COX inhibition has permitted the understanding that the extent on how much patients are exposed (magnitude and duration) is substantial determinant of a much raised risk of nonfatal MI [49]. Different study outcomes make a strong foundation to suggest the possible strategy for the treatment and prevention of cardiovascular hazards in the patient population with different pathologies of vascular system along with various inflammatory conditions [50].

Since Ibuprofen proves to interrupt the Aspirin effects which are anti-platelet therefore shunning the concomitant use of Ibuprofen is recommended [51,52]. If Aspirin is prescribed to a high risks patient of vascular incidents, Naproxen along with a proton pump inhibitor must be administered before two hours of aspirin. When choosing appropriate treatment in different patient traits, NSAIDs must be considered cautiously. Diclofenac showed highest mortality and morbidity in patients with increased cardiovascular risk while on the other hand naproxen serves to have least toxicity against cardiovascular system. Hence, there must be a rational prescribing pattern for nonsteroidal anti-inflammatory agents [53].

\section{Current NSAIDS Utilization Pattern}

Rational Therapeutic utilization and patient education plays indispensible role when it comes to use of NSAIDs. Guidelines for the use of NSAIDs have been published by many different organizations 
Citation: Hasnain H, Ali H, Tariq A, Zafar F, Naveed S (2016) NSAIDs; Safety and Risk Assessment in CVS Events, Comparisons and Facts. J Bioequiv Availab 8: 084-088. doi:10.4172/jbb.1000273

and all these recommendations reflects a proper regime that can not only provide an effective pain control but optimal cardiovascular and GI protection along with the evaluation of CV and GI risks factors in patients prior to initiation of COX-2 or NSAIDs [54,55]. that:

Following are the recommendations of FDA regarding NSAIDs

- When COX-2 inhibitors and traditional non-steroidal antiinflammatory drugs (NSAIDs) are to be used for the management of individual patients; they should be prescribed with the lowest effective dose and for the shortest duration.

- They should not be prescribed for high risk patients, e.g., patients with a history of ischemic heart disease, stroke or congestive heart failure, or in patients who have recently undergone coronary artery bypass grafting (CABG).

- All prescription-strength NSAIDs will now display "black box" label warnings for the potential risk of cardiovascular and gastrointestinal adverse effects.

- Treatment with tNSAIDs alone in patients aged less than 65 years who do not have gastrointestinal risk factors is considered appropriate. Co-therapy with a proton pump inhibitors (PPI) or treatment with a COX-2 inhibitor was considered unnecessary in these patients.

- The use of a tNSAID alone was considered inappropriate in any patient with a previous gastrointestinal event and in those who concurrently receive aspirin, steroids or warfarin. These patients should receive tNSAID plus a PPI or a COX-2 inhibitor.

- Use of a COX-2 inhibitor with PPI co-therapy is appropriate only in patients at very high risk, such as those with a previous gastrointestinal event who are taking aspirin, and those who are taking aspirin plus steroids or warfarin [56].

\section{Significant Considerations}

Blood pressure, plasma half-life, dose dependency, interaction with ASA and COX-2 selectivity are few of the many variable factors that have affected CV hazards and risks which are coupled when nonsteroidal anti-inflammatory agents are used [57]. It has been revealed through many observational studies, systematic reviews, meta-analysis and clinical trials that in comparison with other non-selective and COX-2 selective NSAIDs, Naproxen has consistently showed lower risk of CV events. Among non-selective NSAIDs, highest CV risk has been linked with use of Diclofenac. At twice daily regimens and at higher doses, there is evidence showing high risk of CV events associated with celecoxib. When Acetylsalicylic acid is used along with either diclofenac or naproxen, it is proved that there is negligible abatement for protective cardiovascular system however, there founds an interaction between ibuprofen and ASA. Therefore to enhance its anti-platelet activity, Acetylsalicylic acid must get to the patient 30minutes before or 8 hours after ibuprofen use [58-63].

\section{Conclusion}

Due to anti-natriuretic effects as well as the harmful actions of nonsteroidal anti-inflammatory agents on vascular activity of heart, it is found to delegitimize cardiovascular system, along with ineffectiveness of therapeutic agents. Selectivity in COX enzyme inhibition is major factor to be considered when prescribing individualized therapy to patient. So it can be concluded since inhibitors of COX-2 enzyme are associated with various cardiovascular pathologies like CHF, HTN and cardiac arrhythmias, therefore in patients with any of these existing conditions, they must be administered cautiously, by selecting drugs rationally in low doses and less frequently.

\section{References}

1. Vane JR (2000) The fight against rheumatism: from willow bark to COX-1 sparing drugs. J Physiol Pharmacol 51: 573-586.

2. Grosser T, Smyth EM, FitzGerald GA (2001) Analgesic-antipyretic and antiinflammatory agents and drugs employed in the treatment of Gout. In: Hardman JG, Limbird LE (Eds). Goodman and Gilman's the pharmacologic basis of therapeutics: McGraw-Hill.

3. Harirforoosh S, Jamali $F$ (2005) Effect of nonsteroidal anti-inflammatory drugs with varying extent of COX-2-COX-1 selectivity on urinary sodium and potassium excretion in the rat. Can J Physiol Pharmacol 83: 85-90.

4. Martel-Pelletier J, Pelletier JP, Fahmi H (2004) New insights into prostaglandin biology. J Rheumatol 31: 14-16.

5. DeWitt DL, el-Harith EA, Kraemer SA, Andrews MJ, Yao EF, et al. (1990) The aspirin and heme-binding sites of ovine and murine prostaglandin endoperoxide synthases. J Biol Chem 265: 5192-5198.

6. Shimokawa T, Smith WL (1992) Prostaglandin endoperoxide synthase. The aspirin acetylation region. J Biol Chem 267: 12387-12392.

7. Shimokawa T, Smith WL (1991) Essential histidines of prostaglandin endoperoxide synthase. His-309 is involved in heme binding. J Biol Chem 266 : 6168-6173.

8. Shimokawa T, Kulmacz RJ, DeWitt DL, Smith WL (1990) Tyrosine 385 of prostaglandin endoperoxide synthase is required for cyclooxygenase catalysis. J Biol Chem 265: 20073-20076.

9. Toh H (1989) Prostaglandin endoperoxide synthase contains an EGF-like domain. FEBS Lett 258: 317-319.

10. DeWitt DL, Meade EA, Smith WL (1993) PGH synthase isoenzyme selectivity: the potential for safer nonsteroidal antiinflammatory drugs. Am J Med 95: 40S-44S.

11. Doroudi R, Gan LM, Selin Sjögren L, Jern S (2000) Effects of shear stress on eicosanoid gene expression and metabolite production in vascular endothelium as studied in a novel biomechanical perfusion model. Biochem Biophys Res Commun 269: 257-264.

12. Lim H, Paria BC, Das SK, Dinchuk JE, Langenbach R, et al. (1997) Multiple female reproductive failures in cyclooxygenase 2-deficient mice. Cell 91: 197208.

13. Khan KN, Stanfield KM, Harris RK, Baron DA (2001) Expression of cyclooxygenase-2 in the macula densa of human kidney in hypertension, congestive heart failure, and diabetic nephropathy. Ren Fail 23: 321-330.

14. Fitzgerald GA (2003) Prostaglandins, Aspirin, and Related Compounds. In Goldman L, Ausiello D, editors. Cecil Textbook of Medicine: Elsevier Science Health Science division.

15. Warner TD, Giuliano F, Vojnovic I, Bukasa A, Mitchell JA, et al. (1999) Nonsteroid drug selectivities for cyclo-oxygenase-1 rather than cyclo-oxygenase-2 are associated with human gastrointestinal toxicity: a full in vitro analysis. Proc Natl Acad Sci 96:7563-7568.

16. Jordan S, White $\mathrm{J}$ (2001) Non-steroidal anti-inflammatory drugs: clinical issues Nurs Stand 15: 45-52.

17. Lenzer J (2005) FDA advisers warn: COX 2 inhibitors increase risk of heart attack and stroke. BMJ 330: 440 .

18. Ong CKS, Lirk P, Tan CH, Seymour RA (2007) An evidence-based update on non-steroidal anti-inflammatory drugs. Clin Med Res 5: 19-34.

19. Lo V, Meadows SE, Saseen J (2006) When should COX-2 selective NSAIDs be used for osteoarthritis and rheumatoid arthritis? J Fam Pract 55: 260-262.

20. Bombardier C, Laine L, Reicin A, Shapiro D, Burgos-Vargas R, et al. (2000) Comparison of upper gastrointestinal toxicity of rofecoxib and naproxen in patients with rheumatoid arthritis. VIGOR Study Group. N Engl J Med 343: 1520-1528.

21. Silverstein FE, Faich G, Goldstein JL, Simon LS, Pincus T, et al. (2000) Gastrointestinal toxicity with celecoxib vs nonsteroidal anti-inflammatory drugs 
Citation: Hasnain H, Ali H, Tariq A, Zafar F, Naveed S (2016) NSAIDs; Safety and Risk Assessment in CVS Events, Comparisons and Facts. J Bioequiv Availab 8: 084-088. doi:10.4172/jbb.1000273

for osteoarthritis and rheumatoid arthritis: the CLASS study: A randomized controlled trial. Celecoxib Long-term Arthritis Safety Study. JAMA 284: 12471255.

22. Schnitzer TJ, Burmester GR, Mysler E, Hochberg MC, Doherty M, et al. (2004) Comparison of lumiracoxib with naproxen and ibuprofen in the Therapeutic Arthritis Research and Gastrointestinal Event Trial (TARGET), reduction in ulcer complications: randomised controlled trial. Lancet 364: 665-674.

23. Singh G, Fort JG, Goldstein JL, Levy RA, Hanrahan PS, et al. (2006) Celecoxib versus naproxen and diclofenac in osteoarthritis patients: SUCCESS-I Study. Am J Med 119: 255-266.

24. Ray WA, Varas-Lorenzo C, Chung CP, Castellsague J, Murray KT, et al (2009) Cardiovascular risks on nonsteroidal antiinflammatory drugs in patients after hospitalization for serious coronary heart disease. Circ Cardiovasc Qual Outcomes 2: 155-163.

25. Bueno $H$, BardajÃ A, Patrignani P, MartÃn-Merino E, GarcÃa-RodrÃguez LA; Spanish Case-Control Study to Assess NSAID-Associated ACS Risk Investigators (2010) Use of non-steroidal antiinflammatory drugs and typespecific risk of acute coronary syndrome. Am J Cardiol 105: 1102-1106.

26. (2006) Oxford League Table of Analgesics in Acute Pain.

27. Cook RJ, Sackett DL (1995) The number needed to treat: a clinically useful measure of treatment effect. BMJ 310: 452-454.

28. Ong KS, Seymour RA, Yeo JF, Ho KH, Lirk P (2005) The efficacy of preoperative versus postoperative rofecoxib for preventing acute postoperative dental pain: a prospective randomized crossover study using bilateral symmetrical oral surgery. Clin J Pain 21: 536-542.

29. Patrignani $P$, Tacconelli S, Bruno A, Sostres C, Lanas A (2011) Managing the adverse effects of nonsteroidal anti-inflammatory drugs. Clin Pharmacol 4: 605-621.

30. Farkouh ME, Greenberg BP (2009) An evidence-based review of the cardiovascular risks of nonsteroidal anti-inflammatory drugs. Am J Cardiol 103 $1227-1237$.

31. Bresalier RS, Sandler RS, Quan H, Bolognese JA, Oxenius B, et al. (2005) Cardiovascular events associated with rofecoxib in a colorectal adenoma chemoprevention trial. N Engl J Med 352: 1092-1102.

32. Rostom A, Moayyedi P, Hunt R, Canadian Association of Gastroenterology Consensus Group (2009) Canadian consensus guidelines on long-term nonsteroidal anti-inflammatory drug therapy and the need for gastroprotection: benefits versus risks. Aliment Pharmacol Ther 29: 481-496.

33. Knights KM, Mangoni AA, Miners JO (2010) Defining the COX inhibitor selectivity of NSAIDs: implications for understanding toxicity. Expert Rev Clin Pharmacol 3: 769-776.

34. Ungprasert $P$, Matteson EL, Thongprayoon C (2016) Non-aspirin Non-steroida Anti-Inflammatory Drugs and Risk of Hemorrhagic Stroke: A Systematic Review and Meta-Analysis of Observational Studies. Stroke 47: 356-364.

35. Mamdani M, Juurlink DN, Lee DS, Rochon PA, Kopp A, et al. (2004) Cyclooxygenase- 2 inhibitors versus non-selective non-steroidal anti-inflammatory drugs and congestive heart failure outcomes in elderly patients: a populationbased cohort study. Lancet 363: 1751-1756.

36. Trelle S, Reichenbach S, Wandel S, Hildebrand P, Tschannen B, et al. (2011) Cardiovascular safety of non-steroidal anti-inflammatory drugs: network metaanalysis. BMJ 342: c7086.

37. Essex MN, Zhang RY, Berger MF, Upadhyay S, Park PW (2013) Safety of celecoxib compared with placebo and non-selective NSAIDs: cumulative metaanalysis of 89 randomized controlled trials. Expert Opin Drug Saf 12: 465-477.

38. Bennett WM, Henrich WL, Stoff JS (1996) The renal effects of non-steroidal anti-inflammatory drugs: summary and recommendations. Am J Kidney Dis 28 : S56-62.

39. Farkouh ME, Greenberg BP (2009) An evidence-based review of the cardiovascular risks of non-steroidal anti-inflammatory drugs. Am J Cardiol 103: $1227-1237$

40. E-CPS Ottawa (ON): Canadian Pharmacists Association; 2007.

41. NSAID (2011) (Nonselective)/Salicylates In: LexicompOnline Interaction Monograph [intranet database]. Hudson $(\mathrm{OH})$ : Lexi-Comp Inc.

42. Young D (2005) FDA labors over NSAID decisions: panel suggests COX-2 inhibitors stay available. Am J Health Syst Pharm 62: 668-672.
43. (2011) Aspirin In: DRUGDEX System [intranet database]. Version 2.0 Greenwood Village (CO): Thomson Reuters (Healthcare).

44. McGettigan P, Henry D (2006) Cardiovascular risk and inhibition of cyclooxygenase: a systematic review of the observational studies of selective and nonselective inhibitors of cyclooxygenase 2. JAMA 296: 1633-1644.

45. Graham DJ (2006) COX-2 inhibitors, other NSAIDs, and cardiovascular risk: the seduction of common sense. JAMA 296: 1653-1656.

46. GarcÃa RodrÃguez LA, Tacconelli S, Patrignani P (2008) Role of dose potency in the prediction of risk of myocardial infarction associated with non-steroida anti-inflammatory drugs in the general population. J Am Coll Cardiol 52: 16281636.

47. Hippisley-Cox J, Coupland C (2005) Risk of myocardial infarction in patients taking cyclo-oxygenase-2 inhibitors or conventional non-steroidal antiinflammatory drugs: population based nested case-control analysis. BMJ 330 1366

48. Varas-Lorenzo C, Castellsague J, Stang MR, Perez-Gutthann S, Aguado J, et al. (2009) The use of selective cyclooxygenase- 2 inhibitors and the risk of acute myocardial infarction in Saskatchewan, Canada. Pharmacoepidemiol Drug Saf 18: 1016-1025.

49. Weir MR (2002) Renal effects of nonselective NSAIDs and coxibs. Cleve Clin J Med 69 Suppl 1: SI53-58.

50. Grosser T, Fries S, FitzGerald GA (2006) Biological basis for the cardiovascula consequences of COX-2 inhibition: therapeutic challenges and opportunities. J Clin Invest 116: 4-15.

51. GarcÃa RodrÃguez LA, Tacconelli S, Patrignani P (2008) Role of dose potency in the prediction of risk of myocardial infarction associated with nonsteroidal anti-inflammatory drugs in the general population. J Am Coll Cardiol 52: 16281636.

52. Antman EM, Bennett JS, Daugherty A, Furberg C, Roberts H, et al. (2007) Use of non-steroidal anti-inflammatory drugs: an update for clinicians: a scientific statement from the American Heart Association. Circulation 115: 1634-1642.

53. Catella-Lawson F, Reilly MP, Kapoor SC, Cucchiara AJ, DeMarco S, et al. (2001) Cyclooxygenase inhibitors and the antiplatelet effects of aspirin. N Eng J Med 345: 1809-1817

54. Renda G, Tacconelli S, Capone ML, Sacchetta D, Santarelli F, et al. (2006) Celecoxib, ibuprofen and the antiplatelet effect of aspirin in patients with osteoarthritis and ischemic heart disease. Clin Pharmacol Ther 80: 264-274.

55. Fosba EL, Folke F, Jacobsen S, Rasmussen JN, SÃ rensen R, et al. (2010) Cause-specific cardiovascular risk associated with non-steroidal antiinflammatory drugs among healthy individuals. Circ Cardiovasc Qual Outcomes 3: $395-405$.

56. Schnitzer TJ; American College of Rheumatology (2002) Update of ACR guidelines for osteoarthritis: role of the coxibs. J Pain Symptom Manage 23 S24-30.

57. Dubois RW, Melmed GY, Henning JM, Laine L (2004) Guidelines for the appropriate use of non-steroidal anti-inflammatory drugs, cyclo-oxygenase-2 specific inhibitors and proton pump inhibitors in patients requiring chronic antiinflammatory therapy. Aliment Pharmacol Ther 19:197-208.

58. Zhang J, Ding EL, Song Y (2006) Adverse effects of cyclooxygenase 2 inhibitors on renal and arrhythmia events: meta-analysis of randomized trials. JAMA 296: 1619-1632.

59. Solomon SD, Wittes J, Finn PV, Fowler R, Viner J, et al. (2008) Cardiovascular risk of celecoxib in 6 randomized placebo-controlled trials: the cross trial safety analysis. Circulation 117: 2104-2113.

60. Solomon SD, McMurray JJ, Pfeffer MA, Wittes J, Fowler R, et al. (2005) For the Adenoma Prevention with Celecoxib (APC) Study Investigators Cardiovascular risk associated with celecoxib in a clinical trial for colorectal adenoma prevention. N Engl J Med 352: 1071-1080.

61. Grosser T, Fries S, FitzGerald GA (2006) Biological basis for the cardiovascula consequences of COX-2 inhibition: therapeutic challenges and opportunities. J Clin Invest 116: 4-15.

62. Solomon SD, Pfeffer MA, McMurray JJ, Fowler R, Finn P, et al. (2006) Effect of celecoxib on cardiovascular events and blood pressure in two trials for the prevention of colorectal adenomas. Circulation 114: 1028-1035.

63. Kohli P, Steg PG, Cannon CP, Smith SC Jr, Eagle KA, et al. (2014) NSAID use and association with cardiovascular outcomes in outpatients with stable atherothrombotic disease. Am J Med 127: 53-60. 